\title{
Miradas entrecruzadas. La construcción social de la Otredad. Amaia Izaola Argüeso. Barcelona: Edicions Bellaterra, 2017
}

\author{
Lorenzo Cachón Rodríguez \\ Universidad Complutense de Madrid \\ lorenzo.cachon@gmail.com
}

Al terminar de leer Miradas entrecruzadas uno se percata que acaba de leer dos libros, estrechamente relacionados pero distintos. El primero son Miradas; miradas de personas inmigrantes en el País Vasco que, "como lo podemos constatar cada día en nuestra vida cotidiana, resultan ampliamente influidas por la idea que tenemos de aqueIlo que una etiqueta, una categoría, una palabra designa" (Jacqueline Berger), miradas que se miran en las nuestras y de ahí el título del trabajo de Amaia Izaola. El segundo son Voces; voces inmigrantes vascas que cuentan historias migratorias ricas en experiencias. Al transcribir estas voces la autora confiesa estar recordando las palabras de Pierre Bourdieu al inicio de La miseria del mundo: “¿Cómo no experimentar un sentimiento de inquietud en el momento de hacer públicas ciertas palabras privadas, confidencias recogidas en un vínculo de confianza que solo puede establecerse en la relación entre dos personas." La autora se ha encargado de grabar esas voces en el libro para que nosotros podamos oírlas con toda la emoción y la fuerza que trasmiten.

Sólo se puede escribir un libro como Miradas entrecruzadas si su autora tiene detrás un sólido bagaje investigador, una especial sensibilidad con los problemas de las personas más vulnerables y capacidad de escucha en las entrevistas realizadas con las personas inmigrantes. Los tres rasgos confluyen en Amaia Izaola: profesora de sociología en la Universidad del País Vasco e investigadora con gran trayectoria dentro del grupo de investigación "CIVERCITY. Ciudad y diversidad", sus investigaciones se han centrado especialmente en grupos sociales en situación de exclusión. En este trabajo muestra su capacidad para abordar una cuestión de gran relevancia en las sociedades contemporáneas, cual es cómo se produce la construcción social del "otro", con instrumentos teóricos y con métodos cuantitativos y cualitativos. Frente al entrevistador burocrático (criticado precisamente al final de La miseria del mundo), Amaia Izaola logra trasmitir en este libro la emoción empática del investigador que no le priva de lucidez para comprender el hecho social que está estudiando.

De Miradas y de Voces trata este libro. En las primeras, en las Miradas, se podrían recoger tres capítulos que abordan el estudio del subtítulo del libro: "La construcción social de la Otredad". Son el capítulo 1: "La cuestión del Otro: forasteros, extranjeros, extraños y monstruos", en el que se repasan los enfoques teóricos sobre la Otredad; el capítulo 2: "Distintos y distantes: una escala de distancia social a partir de las encuestas", donde se presenta esa escala de distancia social referida a los inmigrantes; y el capítulo 6: "(Re)construcción de la escala de otredad a partir del discurso de las personas inmigrantes". El resto del libro son las V0ces de los inmigrantes: En el capítulo 3, nos van a narrar su "Desplazamiento y recorrido migratorio"; en el 4 nos hablan "De la cultura de allá a la cultura de acá: experiencias y cambios"; y en el 5 de "El mundo de las relaciones sociales y los escenarios de integración". El capítulo 7 de conclusiones completa el libro y allí se funden miradas y voces.

El primer bloque comienza con un capítulo en el que sintetiza con claridad cuatro análisis clásicos de la construcción social de la Otredad. Y así 
va presentado los trabajos de Schütz sobre el "forastero" y de Simmel sobre el "extranjero" (ambos muy citados en los estudios de migraciones) y los de Beck y Bauman sobre el "extraño" y los menos divulgados de Graham, Haraway, Schildrick y Douglas sobre el "monstruo". La autora los sintetiza al final como si hubiera una escala de Otredad en eso cuatro conceptos que entrecomillamos, del forastero al monstruo. Es una lectura posible de esos autores. Otra posibilidad es leerlos como distintos análisis de un mismo fenómeno y ahí el texto de Norbert Elias y J. L. Scotson, The Established and the Outsiders (1965) podría proporcionar una pauta distinta (y común) de interpretación de todos esos análisis. Claro que la reciente traducción española del título de este libro, como Establecidos y marginados (2016) no ayuda nada en el argumento que presentamos; más lo hace la traducción francesa Logiques de l'exclusion (1997). Porque eso es lo que nos muestra Elias: bajo que "lógicas" se produce socialmente la construcción de "los otros".

A continuación, la autora aborda la presentación de una escala de distancia social entre los inmigrantes según su origen a partir de datos de encuestas. Siguiendo la estela, fundamentalmente, de Ios trabajos de Cea D'Ancona y Valles para España y de Aierdi y Moreno para el País Vasco (en el marco de IKUSPEGI, Observatorio Vasco de Inmigración), una explotación de la base de datos de la Primera Macro-Encuesta de la población extranjera en la CAPV (2006-2007) le permite presentar esa escala para mostrar que si Orwell nos enseñó que "unos son más iguales que otros", también se puede decir que hay inmigrantes que son (tratados) como más diferentes que otros. Otros investigadores habían llamado la atención sobre estas "distancias", pero uno de los aciertos de este libro es haber puesto el foco central en esas distancias. Los motivos que señalan los autóctonos para "justificar" esas diferencias con básicamente motivos "culturales". Algunos resultados que la interesante exploración de los datos de IKUSPEGI se comprenderían mejor si se sintetizaran en índices simples fáciles de comparar. Los resultados que se presentan son coherentes con los que ha planteado la literatura que ha analizado la "etnoestratificación" (la llamen así o no) en España. Y unos de los múltiples aciertos de este trabajo, es haber mirado estas miradas tanto desde la perspectiva de los autóctonos como de los inmigrantes mismos. Un camino este de la "distancia social" entre los inmigrantes (como el de la etnoestratificación) que merecen nuevos desarrollos futuros.

En el segundo bloque oímos las voces de los inmigrantes ayudados por la guía de la autora. Y vemos pasar ante nosotros sus vivencias del proceso migratorio. Vivencias que son únicas como recuerda la autora pero que se pueden tipologizar para facilitar su comprensión comparativa, vivencias que tienen a la familia del migrante como la gran actora del proceso aunque el protagonismo lo tenga el/la inmigrante mismo/a, muy en línea de los planteamientos de Stark o Massey. Y la familia también definida por su separación geográfica en el proceso migratorio y por los problemas (institucionales) para reunificarla y los problemas (intrafamiliares) tras conseguirlo. Vemos sus diferentes transiciones laborales donde "cualquier cosa es válida para buscarse la vida"; la evolución de las situaciones residenciales, desde vivir solos en habitaciones de pisos compartidos hasta los problemas que se plantean cuando logran reunir a la familia o los rechazos discriminatorios en la búsqueda de vivienda; oímos pasar la vida en el barrio. Aquí es uno de los momentos en que se muestra muy bien el papel ambivalente, que Portes ha puesto de relieve, que cumplen las redes sociales (familia, amigos, barrio) en los procesos migratorios: por una parte, facilitan la integración sobre todo en los primeros momentos pero, por otra, producen cierto aislamiento porque las constriñen a permanecer dentro del grupo. Como esas mujeres marroquíes llegadas en los últimos años a las que "les resulta más difícil la integración porque que se sienten arropadas por otras mujeres que llevan ya más de veinte años en el País Vasco": arropar y aislar; facilitar un entorno estrecho que puede dificultar uno más amplio. Lo sintetiza muy bien una activista marroquí refiriéndose a la dificultad de integrarse de las mujeres marroquíes recién llegadas: "Les cuesta mucho integrarse porque se sienten muy apoyadas por sus paisanas". Y podemos sentir sus miedos, sobre todo cuando están o han estado en situación de irregularidad administrativa (que se refleja intensamente 
cuando una mujer colombiana confiesa, Ilorando, que "bueno sí que ahora sí estoy en manos de usted" y pregunta que en qué momento van a venir a detenerla). 0 profundas penas que se producen en el proceso como cuando otra inmigrante (en situación irregular) confiesa el dolor que le produjo no haber podido asistir al entierro de su hijo.

Miradas entrelazadas aborda también muchos aspectos de gran actualidad en el debate social y sociológico sobre los inmigrantes y su integración en y con la sociedad vasca, española y europea. Uno de ellos es el ámbito de la cotidianidad como el espacio donde se produce la integración (y el conflicto) con la sociedad de acogida. Y donde la autora señala que "todas (las personas entrevistados) coinciden en señalar los mismos elementos como aquellos que menos les gustan o que más les incomodan de la cultura o de los hábitos de vida de la sociedad vasca: la (mala) educación de los menores y los jóvenes, la falta de respeto hacia las personas mayores, la debilidad de los lazos familiares y, en general, el individualismo típico de esta sociedad". Es muy interesante esta relación de, podríamos decir, diferencias culturales marcadas por los inmigrantes. Estas realidades con las que se encuentran los inmigrantes, cambian profundamente a algunos de ellos (ya lo había señalado Max Weber). Algunos lo notan cuando vuelven a sus países de origen y descubren que "uno es extranjero en su propia tierra" (dice un colombiano) 0 como señala una marroquí: "Sí, ahora cuando viajo a Marruecos soy extranjera: aquí extranjera y allí extranjera". Y esto me lleva a otro aspecto de gran actualidad: los estereotipos. Los inmigrantes argumentan con fundamento para rechazar los estereotipos referidos a su grupo nacional de origen pero... algunos de ellos los aplican a los otros colectivos.

De gran interés resulta el impacto del hecho migratorio en la visión de las personas inmigrantes, mujeres y varones, sobre el papel social de la mujer en nuestras sociedades. Con razón puede señalar la autora que "si en algún aspecto podemos decir que las personas inmigrantes a las que hemos entrevistado han experimentado importantes cambios en la manera de ser y de ver el mundo, este tiene que ver con el papel de la mujer tanto en la vida privada como en la pública". En palabras de una inmigrante boliviana: "Nosotras las mujeres levantamos mucho la cabeza cuando venimos para acá. 0 sea, decimos que ya no nos van a mandar ellos". Y visto desde la perspectiva de un inmigrante varón colombiano: "Ahora muchas veces aquí.... Las mujeres quieren coger las riendas de todo, manejar todo, entonces nosotros no estamos hechos a eso... Uno ya no pinta nada". Ligado con esto está la polémica que hay a nivel europeo sobre el velo musulmán. Algunas mujeres musulmanas aluden explícitamente esta polémica. Y explican su voluntaria decisión de ponerse el velo en algún momento al Ilegar al País Vasco (cuenta Najua que experimentó discriminación en Marruecos por no llevar el velo y la experimenta en el País Vasco por llevarlo) y su visión de la religión musulmana como liberadora para la mujer. Y lo hacen conscientes de las dificultades añadidas que llevar el velo les plantea en la vida cotidiana (como ha ocurrido en el despido de Ana Saidí por ponerse el velo en 2017 en su trabajo el aeropuerto de Palma de Mallorca, el primer caso de despido declarado nulo por discriminación religiosa por el uso del velo islámico en España).

Como muchas de las personas entrevistadas tienen una relación activa con el asociacionismo inmigrante, sus puntos de vista sobre el mismo y las páginas que la autora dedica a la cuestión son de mucho interés. Y en ella se muestra que a pesar de la debilidad de sus estructuras, el asociacionismo inmigrante cumple múltiples papeles de interés para los inmigrantes (lugar de encuentro, soporte, espacio reivindicativo, visibilidad) y para su integración en la sociedad de acogida y para esta sociedad.

Que el libro de Izaola recoja las voces de los inmigrantes es relevante también para el análisis del proceso de integración de los mismos en y con la sociedad vasca de acogida. Claro que se pueden (y se deben) hacer análisis de las situaciones objetivas a que se ven sometidos los inmigrantes, empezando por factores institucionales y por los actos discriminatorios a que se ven sometidos, pero la perspectiva de los inmigrantes mismos en estos procesos es relevante porque no viene determinada solo por aquella situación objetiva sino que incluye factores sociales de resistencia de personas y grupos inmigrantes. Y si "La experiencia personal de 
discriminación afecta al individuo menoscabando su auto-control y competencia personal" (Nekane Basabe et al.), "la autopercepción de integración (por parte de los inmigrantes) supone un importantísimo factor de empoderamiento" (Fundación Encuentro). Y en Miradas entrecruzadas podemos ver ambos aspectos desde las voces de los inmigrantes que nos trasmiten su experiencia. Conviene señalar aquí una especificidad de (algunas de) las 32 personas inmigrantes entrevistadas por la autora. El gran nivel de reflexividad que algunos ofrecen sobre sus experiencias y los planteamientos que en algunos casos cabe calificar de "académicos", derivan de características de algunos de estos entrevistados: algunos son educadores sociales, uno prepara una tesis doctoral, la mayoría con miembros activos de asociaciones de inmigrantes, etc. Es decir, se trata de una "muestra" de inmigrantes que pone de manifiesto la diversidad que los inmigrantes ofrecen en el País Vasco. Pero las voces de todos ellos ofrecen reflexiones relevantes sobre su experiencia migratoria, independientemente de su nivel de estudios.

Miradas entrecruzadas es un libro relevante en la literatura sobre las migraciones internacionales en el País Vasco y en España. Si al principio en cada uno de los epígrafes se hubiera sintetizado la literatura más relevante existente sobre la realidad de la inmigración en España y el País Vasco para facilitar la comprensión de la problemática en cada una de las áreas, los párrafos que la autora incluye al final de prácticamente todos los epígrafes, podrían haber dialogado mejor con la literatura existente poniendo más de relieve las significativas aportaciones que esta investigación hace a la comprensión del fenómeno migratorio.

Al final de su libro la autora podría haber recordado unas palabras de Pierre Bourdieu al final de $L a$ miseria del mundo: "Llevar al nivel de la conciencia los mecanismos que hacen que la vida sea dolorosa, incluso insoportable, no es neutralizarlos; poner de manifiesto las contradicciones, no es resolverlas. Pero, por más escéptico que se pueda ser respecto a la eficacia social del mensaje sociológico, no se puede dar por sentado que no tenga ningún efecto al permitir que los que sufren descubran la posibilidad de atribuir su sufrimiento a causas sociales y sentirse así disculpados; y dando a conocer el notable origen social, colectivamente ocultado, de la desgracia en todas sus formas, incluidas las más íntimas y las más secretas". Estoy seguro de que si las personas entrevistadas por Amaia Izaola se asoman a este libro, comprenderán mejor su propia situación y las causas sociales que la condicionan. Y lo harán, curiosamente para ellas, a través de sus propias palabras. Porque la autora nos ha trasmitido fielmente sus miradas y sus voces. 